\title{
HIPÓTESES ABDUTIVAS ANTEFACTUAIS E MODELAÇÃO PROATIVA DE METAS $^{1}$
}

Fábio José Rauen ${ }^{2}$

\begin{abstract}
RESUMO
Fundamentado na Teoria da Relevância de Sperber e Wilson (1995), apresenta-se neste artigo um primeiro esboço de uma arquitetura descritiva e explanatória para a formulação e a avaliação de hipóteses abdutivas em contextos proativos, a ser denominada de Teoria de Conciliação de Metas. A partir de um exemplo no qual um indivíduo pretende abrir uma porta chaveada, expõe-se o modelo conceitual em quatro estágios - projeção de meta e formulação, execução e checagem de hipótese antefactual - e avaliam-se processos de conciliação conforme contextos formados por cinco categorias de hipóteses abdutivas antefactuais: categóricas, bicondicionais, condicionais, habilitadoras e tautológicas.
\end{abstract}

Palavras-chave: Pragmática Cognitiva. Teoria da Relevância. Teoria de Conciliação de Metas. Modelação Proativa de Metas. Hipóteses Abdutivas Antefactuais.

\section{INTRODUÇÃO}

A Teoria da Relevância (TR) de Sperber e Wilson (1995) fundamenta-se no princípio cognitivo de que a mente humana tende a maximizar a relevância e no princípio comunicativo de que enunciados geram expectativas precisas de relevância. Por relevância define-se uma propriedade dos inputs direcionados à cognição. O processamento de um input num contexto de suposições cognitivas pode gerar efeitos de modificação ou de reorganização dessas suposições. Um input é relevante quando os efeitos cognitivos superam os esforços de seu processamento. Dessa maneira, em contextos iguais, a relevância é maior quando maiores forem os efeitos cognitivos e/ou quando menores forem os esforços de processamento. 
Lindsay e Gorayska (2004, p. 69), por sua vez, argumentam que relevância é um predicado dependente de meta (goal dependent predicate), de modo que indivíduos atribuem relevância a inputs que se conectam com um propósito. Com base nessa premissa, eles formulam uma definição formal de relevância dependente de meta, segundo a qual " $P$ é relevante para $G$ se e somente se $G$ é uma meta e $P$ é um elemento essencial de algum plano que é suficiente para alcançar G".

Para os autores, metas são representações simbólicas e abstratas de estados do mundo que podem ser objetos de planejamento. Elas podem ser cognitivas ou finais. A maioria das metas é parte de uma cadeia complexa de metas. Uma meta cognitiva decorre de, justifica-se por ou contribui para a elaboração ou execução de metas finais, de maneira que sua especificação associa-se a condições de satisfação que o agente acredita estarem alcançadas quando ele se encontra no estado de meta final.

Isso converge com Silveira e Feltes (1999, p. 37), quando as autoras afirmam que as pessoas prestam atenção a estímulos que, em alguma medida, vêm ao encontro de seus interesses ou se ajustam às circunstâncias do momento. Assim, os indivíduos tanto podem estar reagindo a estímulos, muitos dos quais nada contribuíram, como agindo por interesses prévios, e os inputs são processados num contexto que se ajusta a esses interesses. Mais ainda, eles podem intervir deliberadamente nesses contextos esperando que essas intervenções contribuam para atingi-los. Nessas ocasiões, antes de reativos, os indivíduos são proativos.

O mecanismo de interpretação guiado pela relevância tem-se mostrado eficiente para a modelação dos processos cognitivos envolvidos na interpretação de inputs verbais. Uma vez que os indivíduos pretendem obter uma interpretação que satisfaça suas expectativas de relevância ótima (a rigor uma meta), seguindo uma rota de esforço mínimo e baseando-se na codificação linguística, eles enriquecem esses inputs até obter um significado explícito (explicatura) e, eventualmente, obter um significado implícito a partir deste significado explícito (implicatura), terminando o processo quando a interpretação se conforma com suas expectativas de relevância ${ }^{3}$.

Observe-se que essa modelação é essencialmente reativa, pois o mecanismo é mobilizado pela emergência de um enunciado. A meta do emissor é presumida e, em geral, inferida na interpretação, e a meta do receptor restringe-se a mero aperfeiçoamento cognitivo. Além disso, a mobilização de suposições na necessária 
ampliação do contexto cognitivo para derivar as inferências é pouco desenvolvida, reduzindo-se apenas a uma emergência criativa de hipóteses.

Neste artigo, defende-se a hipótese de que a ampliação do contexto cognitivo é abdutiva, e a cognição é movida antes por uma conclusão presumida do que pela emergência de premissas, de maneira que a modelagem dedutiva é apenas parte do processo de avaliação dessas hipóteses abdutivas.

Dado que o objeto destas reflexões é a modelação proativa de metas, argumenta-se que o agente produz uma inferência à melhor solução, numa analogia ao conceito de inferência à melhor explicação, de modo que ele ajusta a premissa que melhor concorre para a consecução da meta. A propósito, a presunção de relevância ótima e o próprio princípio comunicativo de relevância nada mais são do que inferências à melhor explicação para a emergência ostensiva de um enunciado.

Por abdução define-se um processo de raciocínio que parte de uma observação do tipo $x$ é $Q$. Em seguida, infere-se uma hipótese de conexão nomológica entre $P$ e $Q$. Diante disso, conclui-se a hipótese particular de que $x$ é $P$.

Tome-se o caso de uma meta $Q$ qualquer e um indivíduo i que se imagina estar nesse estado de meta $Q$ no futuro. Nesse caso, $x$ é $Q$ equivale a um estado $x$ qualquer que satisfará a expectativa de se atingir a meta $Q$. Ato contínuo, o indivíduo $i$ formula uma hipótese abdutiva de que há uma conexão nomológica entre $P$ e $Q$ e considera uma ação antecedente $P$ como pelo menos suficiente para atingir $Q$. Segue-se que $x$ é $P$, e o indivíduo i executa a ação $P$ na expectativa de atingir $Q$.

Um raciocínio desse tipo é obviamente ampliativo, pois não há garantia de que a conclusão será verdadeira mesmo com premissas verdadeiras. Assim, tanto abduzir causa a um fenômeno observado pode ser uma explicação falsa, quanto projetar uma hipótese abdutiva antefactual pode redundar em flagrante fracasso. Mesmo assim, é sempre mais razoável supor que a ação é pelo menos suficiente para a consecução de uma meta do que supor o contrário, e isso se revela crucial para a sobrevivência do indivíduo e da espécie.

Conforme Psillos (2002, p. 7), aceitar hipóteses abdutivas antefactuais implica superar três problemas: o das múltiplas explicações, o da conexão entre a abdução e a probabilidade da hipótese que ela gera, e o da natureza da explicação.

Em primeiro lugar, se um evento pode ser explicado por muitas hipóteses rivais, uma meta também pode ser atingida por muitas soluções, e a abdução não possuiria ferramentas para restringi-las. Contudo, Psillos (2002, p. 7-8) argumenta 
que o sucesso como os indivíduos abduzem explicações sugere haver mecanismos para classificar hipóteses por suas virtudes explicativas. Para ele, hipóteses explicativas são melhores quando explicam os fatos, são licenciadas por crenças de fundo, são simples, têm poder unificador, são mais testáveis e, principalmente, implicam novas predições. Esses requisitos, que poderiam ser subsumidos por palavras como experiência, bom senso, expertise, etc., apesar de não algorítmicos, permitiriam a classificação de hipóteses ou a emergência de uma única hipótese tomada como a mais plausível. É o que ocorre, por exemplo, na diagnose de problemas mecânicos ou de causas de doenças por profissionais experientes.

Essa argumentação converge com o que Harman (1965) chamou de inferência à melhor explicação e que aqui é estendida como inferência à melhor solução. Argumenta-se que a melhor solução vincula-se a um princípio de plausibilidade. Assim, se uma hipótese abdutiva explicativa $H_{e}$ é aceita quando explica as evidências e nenhuma outra hipótese rival o faz tão bem como $H_{e}$ faz; então, uma hipótese abdutiva antefactual $H_{a}$ é assumida quando sugere atingir uma meta com mais eficiência e nenhuma outra hipótese rival faz isso tão bem como $H_{a}$ faz.

Além disso, argumenta-se que, em situações ad hoc, a primeira hipótese $H_{e}$ ou $H_{a}$ consistente com princípio de relevância, no sentido em que a hipótese $H_{e}$ ou $H_{a}$ é aquela que emerge com menor custo para o efeito fixo de explicar um fato ou atingir uma meta, será aquela assumida como verdadeira.

Em segundo lugar, dado que a abdução é cancelável e bem podem ser falsas as hipóteses $H_{e}$ ou $H_{a}$, por que adotá-las? Segundo Psillos (2002, p. 9), "embora a hipótese possa ser razoavelmente aceita como hipótese mais plausível com base em considerações explicativas (abdução), o grau de confiança nessa hipótese está ligado a seu grau de confirmação posterior". Para o autor, a abdução é a primeira etapa da tentativa de o indivíduo, confrontado com novos eventos, acrescentar suposições plausíveis ao seu corpus de crença (o conhecimento enciclopédico da TR). Quando essas previsões se cumprem, a hipótese abduzida se confirma.

Por fim, no que se refere à explicação, Peirce (1975) observou que a hipótese abduzida torna natural um fato surpreendente. Segundo Psillos (2002, p. 10), uma explicação visa a melhorar a compreensão dos eventos, e isso ocorre quando o indivíduo consegue mostrar como um evento pode caber no nexo causal/nomológico das coisas que ele aceita. Para ele, os indivíduos removem a surpresa, quando a aceitação de certas hipóteses explicativas e sua incorporação a seu corpus de 
crença ajuda a incluir neste corpus o evento explanandum e. Assim, se a memória enciclopédica $M$ é este corpus de crença, se e é o evento explanandum e se $H$ é uma hipótese potencial, então $H$ deve ser aceita como uma explicação potencial de $e$, se $M$ sozinho não explica e, mas $M \cup H$ o faz (PSILLOS, 2002, p. 10). Isso em tudo converge com a inserção da informação nova ou novamente apresentada no contexto de informações enciclopédicas consideradas pela TR.

Ponderadas essas questões, este artigo visa a propor um primeiro esboço de uma teoria de descrição e explicação da formulação e da avaliação de hipóteses abdutivas antefactuais para a modelação proativa de metas. Para ilustrar o modelo, toma-se o caso de Pedro que pretende abrir a porta chaveada de sua casa.

\section{FORMULAÇÃO DA META}

O primeiro estágio para uma modelação de hipóteses abdutivas antefactuais consiste na formulação da meta, que é assim definida:

[1] O indivíduo i formula uma meta $Q$ no tempo $t_{1}$, tal que:

a) $t_{1}$ representa o tempo da formulação da meta $Q$; e

b) $Q$ é um estado futuro ainda não existente em $t_{1}$.

No exemplo em ilustração, a formulação da meta consiste em algum grau de emergência cognitiva da necessidade de abrir a porta chaveada, a saber:

[1] Pedro $i$ formula a meta $Q$ de abrir a porta chaveada em $t_{1}$.

Essa formulação captura que: a) o processo se inicia em $t_{1}$, que representa 0 tempo da emergência da necessidade de atingir a meta $Q$ de abrir a porta chaveada; e, b) a meta $Q$ de abrir a porta chaveada é uma possibilidade futura ainda não existente no tempo $t_{1}$, o tempo da formulação da meta $Q$. Em outras palavras, a porta em questão ainda está chaveada.

O output da consecução desse estágio pode ser assim representado:

[1] $\quad Q \quad$ abrir a porta, Pedro

\section{FORMULAÇÃO DE UMA HIPÓTESE ABDUTIVA ANTEFACTUAL}

O segundo estágio consiste na formulação de pelo menos uma hipótese abdutiva antefactual para atingir a meta $Q$. Segue-se a formulação: 
[2] O indivíduo $i$ abduz uma hipótese antefactual $H_{a}$ para atingir a meta $Q$ em $t_{2}$, tal que:

a) $t_{2}$ representa o tempo da formulação da hipótese abdutiva antefactual $H_{a}$;

b) $t_{2}$ sucede $t_{1}$

c) a hipótese abdutiva antefactual $H_{a}$ corresponde a uma formulação do tipo "Se $P$, então $Q$ ", de modo que $P$ é uma ação antecedente e $Q$ é um estado consequente;

d) no escopo da hipótese abdutiva antefactual $H_{a}$, a meta $Q$ é admitida pelo indivíduo $i$ como um estado consequente $Q$;

e) no escopo da hipótese abdutiva antefactual $H_{a}$, uma ação antecedente $P$ é admitida pelo indivíduo $i$ como minimamente suficiente para atingir $o$ estado consequente $Q$;

f) a hipótese abdutiva antefactual $H_{a}$ é a primeira formulação consistente com o princípio de relevância, pois é aquela de menor custo de processamento diante do efeito fixo futuro projetado pelo estado consequente $Q$;

g) simultaneamente, a hipótese $H_{a}$ é tomada pelo indivíduo $i$ como a inferência à melhor solução plausível para atingir o estado consequente $Q$.

Com base nessa formulação, ainda de forma incompleta, antecipa-se que:

[2a] Pedro $i$ abduz a melhor hipótese antefactual $H_{a}$ para atingir a meta $Q$ de abrir a porta chaveada no tempo $t_{2}$.

O output da formulação (2a) está incompleto porque não identifica a ação antecedente $P$ admitida por Pedro como minimamente suficiente para atingir 0 estado consequente $Q$ de abrir a porta chaveada. Para dar conta dessa lacuna, considere-se a hipótese de que a memória enciclopédica de Pedro (seu corpus de crença) contém somente o seguinte conjunto de suposições factuais $S_{1-7}$ :

$$
\begin{aligned}
& S_{1}-\text { Usar uma chave abre portas chaveadas; } \\
& S_{2} \text { - Chamar um chaveiro abre portas chaveadas; } \\
& S_{3} \text { - Usar um machado abre portas chaveadas; } \\
& S_{4} \text { - Baixar a maçaneta abre portas chaveadas; } \\
& S_{5} \text { - A porta chaveada é azul; } \\
& S_{6} \text { - A porta chaveada está chaveada; } \\
& S_{7} \text { - A porta chaveada não está chaveada. }
\end{aligned}
$$

Sugere-se aqui que a escolha da melhor hipótese $H_{a}$ no escopo restrito das suposições factuais $S_{1-7}$ decorre do atendimento de pelo menos quatro critérios.

O primeiro critério (ver letra c) considera que a hipótese $H_{a}$ pode ser mapeada por uma formulação hipotética "Se $P$, então $Q$ ", segundo a qual, se uma ação antecedente $P$ for executada, então um estado consequente $Q$ pode ser atingido. As suposições factuais $S_{1-4}$ respeitam esse critério, pois todas podem ser convertidas numa formulação desse tipo. Entretanto, as suposições factuais $S_{5-7}$, além de não serem mapeáveis desse modo, são irrelevantes no sentido defendido por Sperber e Wilson (1995). A suposição $S_{7}$ de que "A porta chaveada não está chaveada" 
contradiz o input perceptivo de que a porta está chaveada e, no confronto entre uma suposição proveniente da memória e um estímulo perceptivo, a suposição obtida pela percepção será mantida (salvo casos de transtornos obsessivo-compulsivos). A suposição $S_{6}$ de que "A porta chaveada está chaveada" é uma tautologia com o estímulo perceptivo, não havendo qualquer ganho cognitivo em processá-la. A suposição $S_{5}$ de que "A porta chaveada é azul" é uma informação desconectada com a meta, pois é difícil de ver qual a contribuição da cor da porta em sua abertura.

O segundo critério (ver letra e) considera que a hipótese $H_{a}$ associa à formulação "Se $P$, então $Q$ " uma ação antecedente $P$ minimamente suficiente para abrir a porta. As suposições factuais $S_{1-4}$ são ações executáveis. Contudo, a suposição $S_{4}$ de que "baixar a maçaneta abre portas chaveadas", embora adequada em casos de portas não chaveadas, além de insuficiente, é inútil para abrir uma porta que se sabe estar chaveada (exceto, mais uma vez, casos de transtornos).

O terceiro e quarto critério (ver letras f e g) operam em conjunto, sugerindo que o indivíduo formulará a hipótese abdutiva $H_{a}$ que é a melhor solução para atingir $Q$ e é a primeira suposição consistente com o princípio de relevância.

A suposição factual $S_{3}$ de que "Usar um machado abre portas chaveadas" é exequível, mas não seria a melhor solução porque se espera de um indivíduo racional que ele abra a porta sem destruí-la. Para $S_{3}$ advir como melhor solução, seria necessário ampliar o contexto: as chaves não estariam disponíveis, a necessidade de abrir a porta deveria ser premente (o que inviabilizaria a opção do chaveiro), poderia haver raiva ou perigo envolvido, etc. Observe-se que todas essas situações implicam aumento de custo de processamento e perdem relevância diante do efeito fixo de meramente abrir uma porta chaveada.

A suposição factual $S_{2}$ de que "Chamar um chaveiro abre portas chaveadas" seguramente atinge a meta, mas é difícil de ver como, diante de uma mera porta chaveada, a primeira solução a vir à mente de Pedro seja a de chamar um chaveiro quando ele tem a disposição uma chave para fazer isso. Para $S_{2}$ advir como melhor solução, seria necessário ampliar o contexto: as chaves não estariam disponíveis, a necessidade de abrir a porta não deveria ser premente, etc. Mais uma vez, essas ampliações demandam aumento no custo de processamento e perdem relevância diante do efeito fixo de meramente abrir uma porta chaveada.

Neste contexto restrito de opções, a suposição factual $S_{1}$ de que "Usar uma chave abre portas chaveadas" seria a melhor solução, pois ela atende a todos os 
quatro critérios: a) $S_{1}$ deixa-se mapear numa formulação hipotética, uma vez que "se Pedro usar a chave, então ele abrirá a porta"; b) $S_{1}$ é uma ação plausível de ser considerada por Pedro como pelo menos suficiente para abrir a porta (pois bem pode ser o caso de a chave não funcionar por inúmeros motivos); c) $S_{1}$ converte-se numa hipótese que, dentre o conjunto restrito $S_{1-7}$ de suposições, é aquela de mais baixo custo de processamento diante do efeito fixo de abrir uma porta chaveada (sem destruí-la, obviamente); e d) $S_{1}$ converte-se numa hipótese que atende 0 critério de melhor solução, visto que não há razões para destruir a porta ou para chamar um chaveiro quando se tem uma chave para abrir a porta.

Portanto, a hipótese abdutiva $H_{a}$ que se comporta como melhor solução (mais relevante, pertinente ou plausível) neste contexto ad hoc é a de que:

[2b] Se Pedro usar a chave, então Pedro abrirá a porta chaveada.

O output de [2b] pode ser assim representado:
[1]
[2] $P$
Q
usar a chave, Pedro
abrir a porta, Pedro
abrir a porta, Pedro

\section{EXECUÇÃo}

O terceiro estágio consiste na provável execução da ação antecedente $P$ :

[3a] O indivíduo $i$ executa $P$ para atingir $Q$ num tempo $t_{3}$, ou

[3b] O indivíduo i não executa $P$ para atingir $Q$ num tempo $t_{3}$, tal que:

a) $t_{3}$ representa o tempo da execução da ação antecedente $P$ no contexto da formulação hipotética "Se $P$, então $Q$ ";

b) $t_{3}$ sucede $t_{2}$;

c) [3b] é o modelo de inação pressuposto por [3a];

d) A inação pode ser voluntária ou involuntária.

A descrição considera que: a) há um tempo próprio $t_{3}$ da execução da ação; b) $t_{3}$ sucede a formulação da hipótese abdutiva antefactual $H_{a}$; c) o modelo positivo no qual a ação $P$ é executada, por definição, pode fazer emergir o modelo negativo no qual a ação $P$ não é executada; e d) apesar da plausibilidade da hipótese, há contextos onde a ação não é possível ou, mesmo sendo possível, não é executada.

A execução é o momento em que Pedro usa ou não a chave para abrir a porta. Argumenta-se neste artigo que o esquema em primeiro plano será o esquema agentivo, a ser denominado de ativo, ou seja, o modelo da execução da ação $P$ no contexto da hipótese $H_{a}$, a saber: Pedro usa a chave para abrir a porta chaveada ${ }^{4}$. 
O modelo não agentivo, a ser denominado de passivo, pode ser acionado em pelo menos duas situações. Na primeira, o indivíduo $i$ não tem condições de executar a ação $P$, como é o caso de a hipótese $H_{a}$ ser abduzida, e Pedro perceber em seguida que não tem a chave. Na segunda, contraditoriamente, há qualquer sorte de conflito ou problema psicológico (hesitações, medos, boicotes pessoais, etc.) que põe em suspeição a própria meta e/ou sua execução. Nesse caso, Pedro, embora formule a meta de abrir a porta chaveada e a hipótese pertinente de usar a chave, mesmo de posse da chave, não a utiliza.

O output do terceiro estágio pode ser visto a seguir:

$\begin{array}{lllll}{[1]} & & \mathrm{Q} & & \text { abrir a porta, Pedro } \\ {[2]} & \mathrm{P} & \mathrm{Q} & \text { usar a chave, Pedro } & \text { abrir a porta, Pedro } \\ {[3]} & \mathrm{P} & & \text { usar a chave, Pedro } & \end{array}$

\section{CHECAGEM}

O quarto estágio consiste na checagem dedutiva da formulação hipotética:

[4a] Considerando-se [2] 'Se $P$, então $Q$ " e [3a] $P$, o indivíduo $i$ atinge $Q$ ' num tempo $t_{4}$, ou

[4b] Considerando-se [2] "Se $P$, então $Q$ " e [3b] $\neg P$, o indivíduo $i$ atinge $\neg Q$ ' num tempo $t_{4}$, tal que:

a) $t_{4}$ representa o tempo da consecução da meta $Q$;

b) $t_{4}$ sucede $t_{3}$.

c) [4a] é o modelo de consecução da ação $P$ de [3a] e [4b] é o modelo de consecução da inação $\neg P$ de [3b];

d) Q' representa o resultado da ação $P$ de [3a] e $\neg Q$ ' representa o resultado da inação $\neg P$ de [3b];

e) Q' ou $\neg Q$ 'é uma realidade em $t_{4}^{5}$.

O quarto estágio consiste na avaliação da (in)ação antecedente $P$ no escopo dedutivo da formulação hipotética "Se $P$, então $Q$ ", o que conflui com o módulo dedutivo de Sperber e Wilson (1995). Quer o indivíduo opte ou não pela consecução da ação antecedente $P$, as consequências serão avaliadas dedutivamente dentro do escopo da hipótese abdutiva. Assim, no cenário [4a] (Q; Se P, então Q; P), Pedro avalia se a porta se abre com a chave; e no cenário não agentivo [4b] $(\neg Q$; $S e \neg P$, então $\neg Q ; \neg P$ ), Pedro avalia se a porta não se abre quando ele não usa a chave ${ }^{6}$.

O output do quarto estágio em [4a] pode ser visto a seguir:

$\begin{array}{lllll}{[1]} & & \text { Q } & & \text { abrir a porta, Pedro } \\ {[2]} & P & \text { Q } & \text { usar a chave, Pedro } & \text { abrir a porta, Pedro } \\ {[3]} & \text { P } & & \text { usar a chave, Pedro } & \\ {[4]} & & \text { Q' } & & \text { porta aberta, Pedro }\end{array}$




\section{AVALIAÇÃO: CONCILIAÇÃO DE METAS E CONFIRMAÇÃO DE HIPÓTESES}

Diante do output do quarto estágio, é possível avaliar tanto a consecução da meta $Q$ como a hipótese abdutiva antefactual $H_{a}$. Nessa avaliação, podem ser considerados dois conceitos: 0 de conciliação de metas e o de confirmação de hipóteses. Por conciliação ou satisfação de metas define-se o estado em que a realidade $Q^{\prime}$ em $t_{4}$ corresponde com a meta $Q$ em $t_{1}$, isto é, o resultado da ação $P$ é semelhante ao resultado imaginado pelo indivíduo i. Por confirmação da hipótese abdutiva antefactual $H_{a}$ define-se o estado em que a realidade $Q$ ' em $t_{4}$ corresponde com a hipótese $H_{a}$ em $t_{2}$, ou seja, o resultado da ação $P$ corrobora a hipótese abdutiva antefactual $H_{a}$ de que a ação $P$ causa o efeito $Q$.

Considerados esses conceitos, podem ser observadas quatro possibilidades. Numa conciliação ativa [5a], o indivíduo $i$ executa a ação $P$ no contexto da hipótese $H_{a}$, e a realidade $Q$ ' em $t_{4}$ concilia-se com a meta $Q$ em $t_{1}$ e confirma a hipótese $H_{a}$ em $t_{2}$. Numa inconciliação ativa [5b], o indivíduo $i$ executa a ação $P$ no contexto da hipótese $H_{a}$, e a realidade $\neg Q$ ' em $t_{4}$ não se concilia com a meta $Q$ em $t_{1}$ e não confirma a hipótese $H_{a}$ em $t_{2}$. Numa conciliação passiva [5c], o indivíduo $i$ não executa a ação $P$ no contexto da hipótese $H_{a}$, e a realidade $Q$ ' em $t_{4}$, mesmo assim, concilia-se com a meta $Q$ em $t_{1}$, embora, tecnicamente, não rejeite a hipótese $H_{a}$ em $t_{2}$. Numa inconciliação passiva [5d], por fim, o indivíduo $i$ não executa a ação $P$ no contexto da hipótese $H_{a}$, e a realidade $\neg Q$ ' em $t_{4}$ não se concilia com a meta $Q$ em $t_{1}$, embora confirme hipótese $H_{a}$ em $t_{2}$.

As quatro situações podem ser visualizadas na figura 1 a seguir:

\section{Figura 1 - Possibilidades de consecução de metas}

\begin{tabular}{|l|r|r|r|r|r|r|r|r|}
\hline Estágios & [5a] conciliação ativa & \multicolumn{2}{|c|}{ [5b] inconciliação ativa } & [5c] conciliação passiva & \multicolumn{2}{|c|}{ [5d] inconciliação passiva } \\
\hline$[1]$ & & $\mathrm{Q}$ & & $\mathrm{Q}$ & & $\mathrm{Q}$ & $\mathrm{Q}$ \\
\hline$[2]$ & $\mathrm{P}$ & $\mathrm{Q}$ & $\mathrm{P}$ & $\mathrm{Q}$ & $\mathrm{P}$ & $\mathrm{Q}$ & $\mathrm{P}$ & $\mathrm{Q}$ \\
\hline$[3]$ & $\mathrm{P}$ & & $\mathrm{P}$ & & $\neg \mathrm{P}$ & & $\neg \mathrm{P}$ & \\
\hline$[4]$ & & $\mathrm{Q}^{\prime}$ & & $\neg \mathrm{Q}^{\prime}$ & & $\mathrm{Q}^{\prime}$ & & $\neg \mathrm{Q}^{\prime}$ \\
\hline
\end{tabular}

Em termos simples: na conciliação ativa [5a], Pedro usa a chave, e a porta se abre; na inconciliação ativa [5b], Pedro usa a chave, mas a porta não se abre; na 
conciliação passiva [5d] Pedro não usa a chave, e, mesmo assim, a porta se abre; e na inconciliação passiva [5d], Pedro não usa a chave, e a porta não se abre.

\section{RELEVÂNCIA DAS CONSECUÇÕES}

Quando se avaliam os efeitos cognitivos da conciliação de metas e da confirmação de hipóteses abdutivas, podem-se projetar quatro situações.

No caso da conciliação ativa [5a], Pedro atinge a meta $Q$ e confirma a hipótese $H_{a}$ de que a chave abre a porta. Essa hipótese é fortalecida e estocada na memória enciclopédica como uma suposição factual a ser acionada em situações futuras. Quanto mais conciliações, menor será o custo de processamento dessa suposição factual e maior a probabilidade de ela ser a primeira hipótese abdutiva a ser acionada em contextos similares (hábito, experiência, expertise, etc.). Além disso, o indivíduo volta-se a metas proativas ou demandas reativas subsequentes. No exemplo em questão, é provável que Pedro perca seu interesse por portas e chaves (elas deixam de ser relevantes) e passe a dedicar atenção a outras questões viabilizadas pela abertura da porta.

No caso de uma inconciliação ativa [5b], a hipótese $H_{a}$ é rejeitada (e, embora um revés não devesse levar Pedro a desconfiar de todas as chaves, a hipótese geral é pelo menos enfraquecida). Por outro lado, a falta de conciliação ganha relevância ao pôr o indivíduo no dilema entre desistir ou perseverar na consecução da meta. Nesta situação, o indivíduo pondera a força das suposições $Q$ e $\neg Q$ ' e, conforme prediz a TR, a suposição mais forte prevalece. No caso de $\neg$ Q' prevalecer, Pedro desiste da meta. No caso de $Q$ prevalecer, emerge um novo problema. Pedro precisa abduzir uma nova hipótese para abrir a porta, e, no conjunto restrito de suposições $S_{1-7}$, a hipótese de chamar um chaveiro poderia ser considerada com mais cuidado. Além disso, a falta de conciliação pode levar Pedro a formular uma hipótese abdutiva pós-factual, uma inferência à melhor explicação plausível (a chave não é correta, há uma tranca adicional, a fechadura não está funcionando etc.).

No caso da conciliação passiva [5c], a hipótese $H_{a}$ fica suspensa. A rigor, ela não pode ser rejeitada, pois se trata da falácia da negação do antecedente de uma implicação material. A conciliação passiva pode redundar na mesma consequência da conciliação ativa ou pode ganhar relevância justamente em função de a meta ter sido atingida apesar da inação. Essa repentina conciliação, quando involuntária, 
pode demandar uma explicação abdutiva pós-factual (alguém abriu a porta por dentro, ela não estava de fato chaveada, houve uma forte corrente de ar, etc.); ou pode gerar novos problemas, quando a inação decorreu de hesitações, medos, etc.

No caso da inconciliação passiva [5d], às avessas, a hipótese $H_{a}$ é confirmada, fortalecida e estocada na memória enciclopédica como uma suposição factual a ser acionada em situações futuras, por mais que o indivíduo não tenha executado a ação antecedente $P$. Supostamente, segue-se o dilema da inconciliação ativa, quando a inação é involuntária, ou demandas psicológicas, quando a inação é voluntária.

\section{MODULAÇÕES}

Um corolário da aplicação dos conceitos de conciliação e de confirmação é a consideração de uma modulação na confiança com que os indivíduos se lançam a hipóteses abdutivas antefactuais. Defende-se, aqui, a hipótese de que é possível formular uma gradação que oscila desde a consideração de uma hipótese categórica até uma hipótese tautológica, bem como a hipótese de que essa modulação pode lançar luzes para descrever e explicar a relação controversa que os indivíduos possuem com enunciados do tipo "Se $P$, então $Q$ ".

Antes, contudo, toma-se por formulação, esquema ou enunciado hipotético toda e qualquer proposição que possa ser parafraseada por enunciados do tipo "Se $P$, então $Q$ '. Uma proposição categórica pode ser tomada como hipotética quando vertida nessa formulação (por exemplo: "chaves abrem portas” pode ser convertido por "se algo é uma chave, então esse algo abre portas"). Defende-se, aqui, a hipótese de que se um enunciado desse tipo é uma suposição factual e se esse enunciado foi inserto num esquema abdutivo antefactual, então esse enunciado é, por default, uma hipótese categórica.

Uma hipótese abdutiva categórica é uma formulação $P \Leftrightarrow Q^{7}$, cuja tabela verdade incide verdade somente quando $P$ e $Q$ são verdadeiros. A hipótese defendida aqui é a de que, salvo modulações, uma hipótese abdutiva antefactual $H_{a}$ emerge como categórica. Nesse caso $P$ e $Q$ são suficientes, necessários e certos, e a única consecução admitida pelo indivíduo é a de uma conciliação ativa [5a].

Numa hipótese abdutiva bicondicional $P \leftrightarrow Q$, é possível serem verdadeiros os casos em que $P$ e $Q$ são simultaneamente verdadeiros ou falsos. Hipóteses 
abdutivas se revelam bicondicionais nas inexecuções de $P$, seja nos casos de problemas involuntários ou de dilemas voluntários. Nesses casos, admitem-se inconciliações passivas [5d], e a mera consideração da possibilidade $\neg P \rightarrow \neg Q$, enfraquece a formulação hipotética, pois $P$ e $Q$ passam agora a ser suficientes e necessários mas não certos.

Numa hipótese abdutiva condicional $P \rightarrow Q$, a ação antecedente $P$ se revela suficiente, mas não necessária para o estado consequente $Q$, de forma que a implicação material se aplica. Nesse caso, há um novo enfraquecimento da força da hipótese abdutiva, porque o indivíduo passa a admitir conciliações passivas [5c].

Numa hipótese abdutiva habilitadora $P \leftarrow Q^{8}$, a ação antecedente $P$ se revela necessária, mas não suficiente para atingir o estado consequente $Q$. Trata-se de uma ação $P$ que habilita, mas não garante a consecução $Q$. Isso permite descrever inconciliações ativas [5b].

Por fim, numa hipótese abdutiva tautológica $P-Q^{9}$, ambos $P$ e $Q$ são suficientes, mas não necessários, modelando situações do tipo "Se $P$, então possivelmente Q", onde todos os tipos de consecução [5a-5d] são possíveis.

Essas possibilidades podem ser resumidas nas tabelas verdade da figura 2 :

Figura 2 - Modulação de enunciados hipotéticos: tabela de verdade

\begin{tabular}{cr|rrrrr}
\hline $\begin{array}{c}\text { Variáveis } \\
P\end{array}$ & $Q$ & Categórica & Bicondicional & Condicional & Habilitadora & Tautológica \\
& $P \Leftrightarrow Q$ & $P \leftrightarrow Q$ & $P \rightarrow Q$ & $P \leftarrow Q$ & $P-Q$ \\
\hline $\mathbf{V}$ & $\mathbf{V}$ & $\mathrm{V}$ & $\mathbf{V}$ & $\mathrm{V}$ & $\mathrm{V}$ & $\mathrm{V}$ \\
\hline $\mathrm{F}$ & $\mathrm{V}$ & $\mathrm{F}$ & $\mathrm{F}$ & $\mathrm{V}$ & $\mathrm{F}$ & $\mathrm{V}$ \\
$\mathrm{V}$ & $\mathrm{F}$ & $\mathrm{F}$ & $\mathrm{F}$ & $\mathrm{F}$ & $\mathrm{V}$ & $\mathrm{V}$ \\
$\mathrm{F}$ & $\mathrm{F}$ & $\mathrm{F}$ & $\mathrm{V}$ & $\mathrm{V}$ & $\mathrm{V}$ & $\mathrm{V}$ \\
\hline
\end{tabular}

A descrição e a explicação dos sucessivos reveses da hipótese abdutiva ilustrada nesse artigo decorrem dessas observações. Argumenta-se que, no estágio [2], a hipótese abdutiva antefactual é tomada pelo indivíduo como categórica $(P \Leftrightarrow Q)$ por default, de forma que a chave certamente permitirá abrir a porta. Tomada a decisão por usar a chave, Pedro pode não encontrá-la. Nesse caso, a hipótese se revela bicondicional $(P \leftrightarrow Q)$. Além disso, também pode ser o caso de alguém abrir a porta do outro lado sem que Pedro tenha usado a chave. Isso faz emergir à mente que o uso da chave não é única forma de abri-la, e a hipótese se revela condicional $(\mathrm{P} \rightarrow \mathrm{Q})$. Por outro lado, também pode ser o caso de Pedro usar a chave e se dar 
conta de que outra pessoa colocou uma tranca adicional. Agora, embora a chave ainda seja necessária, não é suficiente para abrir a porta, o que conforma a hipótese como habilitadora $(P \leftarrow Q)$. Por fim, após considerar todas as possibilidades, Pedro bem pode concluir que a hipótese é tautológica $(P-Q)$.

\section{CONSIDERAÇÕES FINAIS}

Neste artigo apresentou-se um primeiro esboço para a modelação de hipóteses abdutivas antefactuais conectando, do ponto de vista simbólico, a noção de relevância com a noção de meta. Defendeu-se a hipótese de que a ampliação do contexto cognitivo para o processamento de metas é abdutiva, e a cognição é movida antes por uma conclusão presumida do que pela emergência de premissas. Posto isso, a modelagem dedutiva proposta pela TR integra o processo de checagem dessas hipóteses abdutivas. Na modelação proativa de metas, o agente abduz uma hipótese ou inferência à melhor solução - princípio de plausibilidade que, simultaneamente, é a solução com menor custo diante do efeito fixo da meta princípio de relevância. Dessa maneira, o próprio princípio comunicativo de relevância é uma hipótese abdutiva dessa espécie, e decorre dessa abdução o mecanismo de interpretação guiado pela relevância.

Com base nesses princípios, propôs-se uma modelação proativa de metas consistindo de quatro etapas: formulação de meta, formulação de uma hipótese abdutiva antefactual, execução e checagem. Do processo de checagem, sugeriramse quatro tipos de consecução conforme as noções de conciliação dos resultados com a meta e de confirmação da hipótese: conciliação ativa, inconciliação ativa, conciliação passiva e inconciliação passiva.

Esses tipos de consecução levaram a propor uma modelação de enunciados hipotéticos “Se P, então Q". Levantou-se a hipótese de que, por padrão, hipóteses abdutivas emergem como categóricas $(P \Leftrightarrow Q)$ e modelam conciliações ativas. Diante de problemas ou dilemas, essa formulação torna-se bicondicional $(P \leftrightarrow Q)$, admitindose inconciliações passivas. Quando $P$ é apenas suficiente, a formulação torna-se condicional $(P \rightarrow Q)$, admitindo-se conciliações passivas. Quando $P$ é necessário, mas não garante $Q$, a formulação torna-se habilitadora $(P \leftarrow Q)$, admitindo-se 
inconciliações ativas. Por fim, quando todas as possibilidades são plausíveis a formulação torna-se tautológica $(P-Q)$.

Dito isso, argumenta-se que, ao processar qualquer enunciado hipotético "Se $\mathrm{P}$, então Q", os indivíduos são capazes de construir ad hoc que tipo de conexão há entre $P$ e $Q$. Isso explicaria como os seres humanos modulam diferentes significados e deles diferentes inferências para essa mesma formulação enunciativa.

Por outro lado, ainda que de forma especulativa, vale também questionar se 0 modelo abdutivo/dedutivo aqui proposto poderia ser extrapolado para o tratamento reativo de problemas. Dessa maneira, instado por demandas, o indivíduo não somente poderia abduzir a melhor explicação, quando sua cognição se dirige à modelação de causas, mas "abduzir" a melhor consecução, quando sua cognição se dirige à modelação das consequências, uma vez que, exceto pela emergência de uma meta, o raciocínio parte de um evento particular, passando por uma formulação hipotética de conexão causal/nomológica e chega a uma conclusão particular.

Por fim, resta dizer que o modelo nada mais é do que um conjunto de hipóteses abdutivas que se propõe a concorrer com outros conjuntos de hipóteses. Resta agora pôr essas hipóteses à fase de checagem.

\section{NOTAS}

${ }^{1} \mathrm{O}$ autor agradece as contribuições essenciais das estudantes Andreia da Silva Bez, Sandra Vieira e Suelen Francez Machado Luciano na formulação das hipóteses e do modelo e na revisão desse ensaio.

2 Doutor em Letras/Linguística pela Universidade Federal de Santa Catarina (UFSC) com pósdoutorado em Letras pela Pontifícia Universidade Católica do Rio Grande do Sul (PUCRS). Docente e Coordenador do Programa de Pós-graduação em Ciências da Linguagem da Universidade do Sul de Santa Catarina (PPGCL/UNISUL). E-mail: fabio.rauen@unisul.br.

${ }^{3}$ No mecanismo de interpretação guiado pelo conceito de relevância, destaca-se o módulo dedutivo, ou seja, um módulo que captura suposições obtidas da percepção ou da memória e deduz conclusões de modo não trivial e não demonstrativo por regras de eliminação do tipo eliminação-e, eliminação-ou e modus ponens.

\footnotetext{
${ }^{4}$ Acompanha-se a argumentação de Johnson-Laird e Byrne (2002) para quem, no contexto da teoria de modelos mentais, modelos alternativos à formulação positiva ficam em notas de rodapé e, em geral, são esquecidos.

${ }^{5}$ A expressão Q' destaca que a consecução da meta é sempre em alguma medida diferente de sua projeção.

${ }^{6}$ Diga-se de passagem, aliás, que testar novamente a maçaneta $S_{4}$, apesar de inútil, é um comportamento típico quando alguém se vê sem chaves.
} 
${ }^{7}$ Propõe-se, aqui, $\Leftrightarrow$ como um símbolo lógico que captura a conexão suficiente, necessária e certa entre os termos da proposição.

${ }^{8}$ O termo é um empréstimo de Johnson-Laird e Byrne (2002, p. 661). Outra formulação poderia ser $Q \rightarrow P$.

${ }^{9} \mathrm{O}$ termo é um empréstimo de Johnson-Laird e Byrne (2002, p. 660-661). Propõe-se, aqui, - como um símbolo lógico que captura a ausência de conexão necessária entre os termos da proposição.

\title{
ANTE-FACTUAL ABDUCTIVE HYPOTHESES AND PROACTIVE MODELING OF GOALS
}

\begin{abstract}
Based on Sperber and Wilson's (1995) relevance theory, I outline in this paper a goal conciliation theory in order to describe and explain the formulation and evaluation of ante-factual abductive hypotheses in proactive contexts. With an example in which an individual intends to open a locked door, I present this conceptual architecture in four stages - goal designing, and hypothesis formulation, execution and checking; and also explain conciliation processes in contexts of categorical, biconditional, conditional, enabling, and tautological ante-factual abductive hypotheses.
\end{abstract}

Keywords: Cognitive Pragmatics. Goal Conciliation Theory. Relevance Theory. Proactive Modeling of Goals. Ante-factual Abductive Hypotheses.

\section{REFERÊNCIAS}

HARMAN, G. The inference to the best explanation. Philosophical Review, v. 74, p. 88-95, 1965.

JOHNSON-LAIRD, P. N.; BYRNE, R. M. J. Conditionals: a theory of meaning, pragmatics, and inference. Psychological Review, v. 109, n. 4, p. 646-678, 2002.

LINDSAY, R.; GORAYSKA, B. Relevance, goal management and cognitive technology. In: GORAYSKA, B; MEY, J. Cognition and technology: co-existence, convergence, and co-evolution. Amsterdam: J. Benjamins, 2004.

PEIRCE, C. S. Semiótica e filosofia. São Paulo: Cultrix; Edusp, 1975. 
PSILLOS, S. Simple the best: a case for abduction. In: KAKAS, A. C.; SADRI, F. (Eds.). Computational logic: logic programming and beyond. Berlin: Springer-Verlag, 2002. p. 605-626. Disponível em: <http://www.phs.uoa.gr/ psillos/>. Acesso em: 2 set. 2013.

SILVEIRA, J. R. C.; FELTES, H. P. M. Pragmática e cognição: a textualidade pela relevância e outros ensaios. 2. ed. Porto Alegre: Edipucrs, 1999.

SPERBER, D.; WILSON, D. Relevance: communication \& cognition. 2. ed. Oxford: Blackwell, 1995. 